\title{
Career Preparation Behaviors and Career Considerations Based on Career Attitude Types of Cosmetology Major College Students
}

\author{
Seung-Eun Choi \\ Department of Fashion, Graduate School of Design, Sungkyunkwan University, Seoul, Korea
}

\author{
Corresponding author: Seung-Eun Choi, \\ Department of Fashion, Graduate School \\ of Design, Sungkyunkwan University, 25-2 \\ Sungkyunkwan-ro, Jongno-gu, Seoul 03063, \\ Korea \\ Fax: +82 336515876 \\ Email: makeyouup223@naver.com
}

Received February 13, 2017

Revised May 5, 2017

Accepted May 24, 2017

Published September 30, 2017

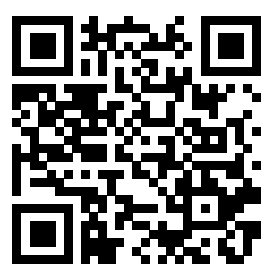

\begin{abstract}
Purpose: This study aims to identify career preparation behaviors and career considerations based on career attitude types of cosmetology major college students. Methods: A total of 205 questionnaires were used for the final analysis. Moreover, factor analysis, reliability analysis, cluster analysis, and variance analysis were conducted using the Statistical Package for the Social Sciences (SPSS) program. Results: The career attitude type was sub-categorized into four types: career confidence, career indifference, career determinacy, and career independence.preparation. The career confidence type was at the highest level for planning.preparation and search-conversation factors, and at the lowest level for counseling. practice factor in career preparation behaviors. In career considerations, all factors were considered important when compared to other groups; however, the most important factor was personal-image. Career indifference type was at the lowest level when compared to other groups in terms of all factors of career preparation behaviors except counseling practice factor. In career considerations, compensation -welfare factor was the most important. In case of career determinacy type, counseling practice factor in career preparation behaviors was relatively high when compared to other groups, and among career considerations factors compensation-welfare factor was relatively lower than other groups. Career independence-preparation type showed a moderate degree of career preparation behaviors and career considerations when compared to other groups. Conclusion: College students majoring in cosmetology showed differences in career preparation behaviors and career considerations based on career attitude types. Therefore, it is necessary to use them for career guidance and career counseling based on their career attitude types.
\end{abstract}

Keywords: Career attitude, Career preparation behaviors, Career considerations, College, Cosmetology major

\section{Introduction}

외모를 중시하는 사회 풍토는 우리나라 미용 산업을 고부가가치 유망 업종으로 자리잡게 해주었다. 한국보건산업진흥원의 뷰티 산 업 결과보고서에 따르면 2011년 뷰티 서비스관련 사업체는 119,139 개, 종사자 수는 182,254 명으로 점점 증가하는 추세로 미용 산업의 양적 발전뿐 아닌 인력 고용 창출의 역할을 하고 있다(Kim et al., 2009). 과거의 미용교육은 기술만을 교육하는 단순한 차원의 교육
이었다면, 현재의 미용교육은 학문의 한 분야로 인정받으며 기술뿐 아닌 지식과 인성을 갖춘 전문가를 양성하는 다차원적 교육을 기반 으로 하고 있다(Hong \& Bang, 2013). 이러한 현상에 따라 미용전공 학과가 신설되며 미용전공자의 수가 증가하였고 이는 미용분야의 인적 자원 증가의 원동력이 되고 있다(Joo \& Chang, 2013).

미용전공은 타 전공보다 전공의 특성이 뚜렷하며, 미용을 전공 한다는 것 자체가 이미 진로가 결정되었다고 여기는 경향이 크다 (Hong, 2012). 따라서 전문대학과 같은 미용전공자 교육기관은 미 
용분야 전문가를 양성하는 핵심적 역할을 담당하고 있다. 그러나 이러한 미용전공자의 양적 증가와 무관하게 미용전공자들은 졸업 후 취업과 진로문제에 직면하며 대부분이 전공인 미용과 무관한 직 종에 종사하고 있어(Kang et al., 2004), 미용전공자가 졸업 후 다 시 적성과 진로에 대해 고민하는 비효율적인 과정을 반복하고 있다 (Lee et al., 2016). 이는 미용 산업의 발전과 인력의 양적 증가가 미 용전공자들의 진로문제 해결과는 무관함을 의미한다(Kang et al., 2004). 또한 학생상담센터 활동보고에 따르면 대학 재학 중 교수와 개 인상담을 하는 원인 중 $1 / 3$ 이 진로 및 적성에 관련된 것으로 파악되어 (Bang \& Park, 2014), 학교 재학 중 학습에 대한 부담과 진로에 대해 결정하고 준비해야 하는 상황에 어려움을 느끼는 것으로 나타났다.

진로를 결정하는 일은 인생에서 가장 중요한 문제로, 단순한 취업 이 아닌 자신의 인생의 전반적인 적성과 흥미를 고려한 진로에 대한 중요성이 높아지고 있다. 대학교 시절은 생애 주기 중 가장 진로에 관심이 많은 시기이므로(Hong, 2012), 미용전공자들의 진로에 대한 연구가 절실하다. 진로란 개인의 생애에서 직업과 그 직업을 이루기 위한 과정을 포함하는 개념이며, 진로태도는 개인이 직업에 대하여 가지는 가치관이자 직업관으로, 넓은 의미로 직업에 대한 정보를 수 집하고 준비하고, 진로를 발견하고, 정착하고 이에 더 나아가 그 직 업을 중단하고 물러나는 모든 단계에서 나타나는 인지적, 태도적 준 비의 정도를 의미한다(Super, 1955).

미용전공자들의 진로에 관한 선행연구는 미용관련학과 재학생들 의 직업선호도에 관한 연구(Kang et al., 2004), 미용학과 학생들의 직업인식도(Son \& Lee, 2004), 미용전공자들의 진로선택 시 고려사 항(Park \& Lee, 2007), 미용관련학과 학생들의 취업의식과 학과만 족도(Choi, 2010), 미용 전공만족도가 진로결정효능감에 미치는 영 향(Bang \& Park, 2014) 등이 있다. 대부분이 전공만족도와 미용전 공자들의 학년, 성별, 연령, 학과와 같은 인구통계학적 특성에 따른
진로에 대한 연구로, 미용전공자들의 진로태도를 유형화한 연구는 미비한 실정이다. 진로와 관련된 사항은 단순한 인구통계학적 요인 에 따라 일관된 결과를 나타내지 않기 때문에, 미용전공자들의 진로 에 대한 가치관과 직업관인 진로태도를 유형화하고 이를 분석한 연 구가 필요하다.

이에 따라 본 연구는 미용전공자들의 진로태도유형을 파악하고 이에 따른 진로준비행동과 취업고려요인에 대하여 파악하고자 한 다. 이러한 연구는 미용전공자들의 졸업 후 미용 산업 진출을 위한 효율적인 진로지도와 진로상담에 도움이 될 것이며, 미용 산업의 인 력관리에 기초자료로 제공될 수 있을 것이다.

\section{Methods}

\section{1. 연구문제}

본 연구는 미용전공 대학생의 진로태도유형에 따른 진로준비행 동, 취업고려요인을 살펴보기 위한 연구로서 다음과 같은 연구문제 를 제시하였다. 첫째, 미용전공자들의 진로태도유형을 알아본다. 둘 째, 진로태도유형에 따른 진로준비행동을 알아본다. 셋째, 진로태도 유형에 따른 취업고려요인을 알아본다.

\section{2. 연구대상 및 자료분석}

본 연구는 서울과 경기도 소재 2 년제 대학 미용전공자를 대상으 로 2016년 6월 1일부터 6월 15일까지 설문지 평가를 실시하였다. 총 250 부의 설문지를 배포하였고, 부적절한 설문지 45 부를 제외한 총 205부를 최종분석에 이용하였다. SPSS 23.0 (BMM, USA)을 이용하 여 요인분석, 신뢰도분석, 군집분석, 분산분석을 실시하였다.

Table 1. Factor analysis of career attitude

\begin{tabular}{|c|c|c|c|c|c|}
\hline Factor & Item & $\begin{array}{l}\text { Factor } \\
\text { loading }\end{array}$ & $\begin{array}{l}\text { Eigen } \\
\text { value }\end{array}$ & VE/CV & $\begin{array}{c}\text { Reliability } \\
\text { (Cronbach's } \alpha)\end{array}$ \\
\hline \multirow{5}{*}{$\begin{array}{l}\text { Career } \\
\text { independence }\end{array}$} & I will choose my job according to my decisions. & 0.865 & \multirow{5}{*}{5.056} & \multirow{5}{*}{$\begin{array}{l}42.130 / \\
42.130\end{array}$} & \multirow{5}{*}{0.851} \\
\hline & No matter what others say, I have to choose what I want to do. & 0.832 & & & \\
\hline & I will choose the job I like. & 0.771 & & & \\
\hline & I am confident that I will be recognized by my boss at work. & 0.681 & & & \\
\hline & I can get the job I want if I try. & 0.668 & & & \\
\hline \multirow{3}{*}{$\begin{array}{l}\text { Career } \\
\text { determinacy }\end{array}$} & I already have a career, so I do not have to worry about career choice. & 0.955 & \multirow{3}{*}{2.097} & \multirow{3}{*}{$\begin{array}{l}17.473 / \\
59.603\end{array}$} & \multirow{3}{*}{0.961} \\
\hline & I have made a clear decision regarding my career. & 0.939 & & & \\
\hline & I have already decided what I will do in the future. & 0.905 & & & \\
\hline \multirow{4}{*}{$\begin{array}{l}\text { Career } \\
\text { preparation }\end{array}$} & I have to plan ahead in order to get the job that I want. & 0.832 & \multirow{4}{*}{1.549} & \multirow{4}{*}{$\begin{array}{l}12.909 / \\
72.512\end{array}$} & \multirow{4}{*}{0.781} \\
\hline & $\begin{array}{l}\text { I am interested in the story of a successful person in order to take up } \\
\text { the work that I want to do. }\end{array}$ & 0.708 & & & \\
\hline & I imagine my future work life. & 0.681 & & & \\
\hline & I will do as well as those who are already working in my chosen career. & 0.677 & & & \\
\hline
\end{tabular}

VE, variance explained; CV, cumulative variance. 


\section{3. 측정방법 및 도구}

본 연구에서는 진로태도를 측정하기 위해 Crites (1973)의 Career Maturity Inventory (CMI) 척도를 본 연구에 맞게 수정 · 보완한 12 문항을 5 점 척도로 측정하였다. 진로준비행동을 측정하기 위해 Jeon (2015)의 연구를 수정 - 보완한 9문항을 5점 척도로 측정하였 다. 취업고려요인을 측정하기 위해서 Kim \& Ji (2011)의 문항을 재 구성하여 총 13 문항을 5 점 척도로 사용하였다.

\section{Results and Discussion}

\section{1. 미용전공자들의 진로태도요인과 진로태도유형 분류}

2 년제 대학 미용전공자들의 진로태도 12 문항을 주성분분석의 Varimax 회전으로 요인분석 및 신뢰도분석을 실시하였다. 총 3 개 의 요인으로 나타났으며 결과는 Table 1 과 같다. 전체 누적분산율 은 $72.512 \%$ 로 나타났으며 신뢰도는 $0.781-0.961 \%$ 로 내적 일관성 이 있는 것으로 나타났다. 요인1은 진로에 관한 자신감, 독립성에 관한 문항으로 구성되어 '진로독립성'이라 명명하였으며 분산율은 $42.130 \%$, 신뢰도는 $0.851 \%$ 로 나타났다. 요인2는 진로에 대한 확실 한 결정 등에 관련된 문항으로 구성되어 '진로결정성'이라 명명하였
으며 분산율은 $17.473 \%$, 신뢰도는 $0.961 \%$ 로 나타났다. 요인3은 진 로에 대한 계획 및 준비와 관련된 문항으로 '진로준비성'이라 명명하 였으며 분산율은 $12.909 \%$, 신뢰도는 $0.781 \%$ 로 나타났다.

이후 진로태도유형을 분석하기 위해 3 가지 요인을 바탕으로 군 집분석을 실시하였다. 분산분석과 Duncan test를 실시한 결과는 Table 2와 같다. 진로독립성, 진로결정성, 진로준비성의 모든 요인 에서 가장 높은 점수를 나타낸 집단을 '진로확신형'으로 명명하였으 며 35명이 포함되었다. 모든 요인에서 가장 낮은 점수를 나타낸 집 단은 '진로무관심형'으로 명명하였으며 40명이 포함되었다. 또한, 진로결정성요인이 다른 요인보다 상대적으로 높은 점수를 나타낸 집단은 ‘진로결정형'으로 명명하였으며 73명이 포함되었다. 마지막 으로 진로독립성요인과 진로준비성요인이 상대적으로 높게 나타난 집단을 ‘진로독립 · 준비형'으로 명명하였으며 57명이 포함되었다.

\section{2. 진로태도유형에 따른 진로준비행동}

진로준비행동의 요인분석, 신뢰도분석 결과는 Table 3 와 같다. 전 체 누적분산율은 $65.919 \%$ 로 나타났으며 신뢰도는 0.582-0.710\%로 내적 일관성이 있는 것으로 나타났다. 요인1은 진로에 대해 계획을 세우고 정보수집, 학원수강과 같은 진로준비에 관한 문항으로 구성 되어 '계획 · 준비요인'이라 명명하였으며 분산율은 $40.511 \%$, 신뢰도

Table 2. Type classification of career attitude

\begin{tabular}{|c|c|c|c|c|c|}
\hline \multirow[b]{2}{*}{ Career attitude factor } & \multicolumn{4}{|c|}{ Career attitude type } & \multirow[b]{2}{*}{$F$-value } \\
\hline & $\begin{array}{c}\text { Career } \\
\text { confidence type } \\
(\mathrm{N}=35)\end{array}$ & $\begin{array}{c}\text { Career } \\
\text { indifference type } \\
(\mathrm{N}=40)\end{array}$ & $\begin{array}{c}\text { Career } \\
\text { determinacy type } \\
(\mathrm{N}=73)\end{array}$ & $\begin{array}{l}\text { Career independence } \\
\text { preparation type } \\
(\mathrm{N}=57)\end{array}$ & \\
\hline Career independence & $1.187(\mathrm{~A})$ & $-1.045(D)$ & $-0.315(C)$ & $0.408(\mathrm{~B})$ & $78.151^{* * *}$ \\
\hline Career determinacy & $1.380(\mathrm{~A})$ & $-1.152(D)$ & $0.568(B)$ & $-0.766(C)$ & $437.098^{* * *}$ \\
\hline Career preparation & $1.189(\mathrm{~A})$ & $-0.839(D)$ & $-0.365(\mathrm{C})$ & $0.032(\mathrm{~B})$ & $56.754^{* * *}$ \\
\hline
\end{tabular}

${ }^{* * *} p<0.001$; Duncan test $\mathrm{A}>\mathrm{B}>\mathrm{C}>\mathrm{D}$.

Table 3. Factor analysis of career preparation behaviors

\begin{tabular}{|c|c|c|c|c|c|}
\hline Factor & Item & $\begin{array}{l}\text { Factor } \\
\text { loading }\end{array}$ & $\begin{array}{l}\text { Eigen } \\
\text { value }\end{array}$ & $\mathrm{VE} / \mathrm{CV}$ & $\begin{array}{c}\text { Reliability } \\
\text { (Cronbach's } \alpha)\end{array}$ \\
\hline \multirow{3}{*}{$\begin{array}{l}\text { Planning. } \\
\text { preparation }\end{array}$} & I plan and act to achieve my career goals. & 0.884 & \multirow{3}{*}{3.646} & \multirow{3}{*}{$\begin{array}{l}40.511 / \\
40.511\end{array}$} & \multirow{3}{*}{0.710} \\
\hline & $\begin{array}{l}\text { I have planned to gather relevant information about the job of my } \\
\text { interest. }\end{array}$ & 0.797 & & & \\
\hline & $\begin{array}{l}\text { I have taken up a coaching course of an academy for the job I am } \\
\text { interested in. }\end{array}$ & 0.547 & & & \\
\hline \multirow{4}{*}{$\begin{array}{l}\text { Search } \\
\text { conversation }\end{array}$} & I look for qualifications pertaining to my career of choice. & 0.847 & \multirow{4}{*}{1.265} & \multirow{4}{*}{$\begin{array}{l}14.055 / \\
54.566\end{array}$} & \multirow{4}{*}{0.707} \\
\hline & $\begin{array}{l}\text { I browse for information about the job that I am interested in on } \\
\text { the internet. }\end{array}$ & 0.684 & & & \\
\hline & $\begin{array}{l}\text { I have had a conversation with my parents regarding my aptitude } \\
\text { and career choice. }\end{array}$ & 0.571 & & & \\
\hline & $\begin{array}{l}\text { I have had a conversation with my friends regarding my aptitude } \\
\text { and career choice. }\end{array}$ & 0.524 & & & \\
\hline $\begin{array}{l}\text { Counseling. } \\
\text { practice }\end{array}$ & $\begin{array}{l}\text { I have had a counseling session with my professors regarding my } \\
\text { aptitude and career choices. } \\
\text { I have participated in career-related sessions and programs. }\end{array}$ & $\begin{array}{l}0.923 \\
0.468\end{array}$ & 1.022 & $\begin{array}{l}11.353 / \\
65.919\end{array}$ & 0.582 \\
\hline
\end{tabular}

$\mathrm{VE}$, variance explained; $\mathrm{CV}$, cumulative variance. 
는 $0.710 \%$ 로 나타났다. 요인2는 진로에 대해 자격요건, 직업정보에 대한 검색, 부모님과 친구와 진로에 대한 대화에 관한 문항들로 구 성되어 '검색 · 대화요인'으로 명명하였으며 분산율은 $14.055 \%$, 신 뢰도는 $0.707 \%$ 로 나타났다. 요인3은 진로에 대해 상담을 하고 설명 회 등에 참가를 하는 실천행동에 관한 문항으로 구성되어 '상담· 실 천요인'으로 명명하였으며 분산율은 $11.353 \%$, 신뢰도는 $0.582 \%$ 로 나타났다.

이후 진로태도유형에 따른 진로준비행동을 알아보기 위해 분산 분석과 Duncan test를 실시한 결과는 Table 4 와 같다. 진로확신형은 계획 · 준비요인, 검색 - 대화요인이 높았으나 상담 - 실천요인은 가 장 낮게 나타났다. 진로결정형은 검색 - 대화, 계획 · 준비, 상담 - 실 천의 순서로, 진로독립 · 준비형은 계획 · 준비, 검색 · 대화, 상담 · 실천의 순서로 나타났다. 반면 진로무관심형은 검색 - 대화, 계획 · 준비, 상담 - 실천의 순서로 나타났다. 따라서 진로확신형과 진로독 립 · 준비형은 계획 · 준비요인이 진로결정형, 진로무관심형은 검 색 - 대화요인이 가장 높게 나타났지만, 모든 진로태도유형에서 상 담 - 실천요인은 가장 낮게 나타났다. 이는 미용전공자들이 부모님, 친구와는 진로에 관한 대화를 자주 나누지만, 학교 교수님과 진로에 대해 상담하는 행동이 가장 낮게 나타나 Park \& Lee (2007)의 연구 에서 미용관련 직업을 선택할 때 가장 큰 도움을 준 사람으로 가족, 대중매체, 친구, 선배, 교수님의 순서로 나타나 직업 선택 시 가족과 진로에 대한 대화를 많이 하지만 교수님은 가장 낮은 것으로 나타난 본 연구의 결과와 일치한다. 따라서 학생들의 진로행동을 향상시키 도록 학교 교수님과 진로에 대해 부담 없이 상담할 수 있는 취업, 진 로상담 프로그램이 필요하다는 Ryu \& Jeon (2015)의 연구와 맥을 같이한다.

\section{3. 진로태도유형에 따른 취업고려요인}

취업고려요인의 요인분석, 신뢰도분석 결과는 Table 5 와 같다. 전 체 누적분산율은 $74.791 \%$ 로 나타났으며 신뢰도는 $0.733-0.827 \%$ 로 내적 일관성이 있는 것으로 나타났다. 요인1은 휴가, 근무시간, 월급 과 같은 보상과 복지에 관한 문항으로 구성되어 '보상 - 복지요인'이 라 명명하였으며 분산율은 $30.017 \%$, 신뢰도는 $0.802 \%$ 로 나타났다. 요인2는 직원, 운영자의 인성과 실력 업체이미지에 관한 문항들로 구성되어 ‘인적 - 이미지요인’으로 명명하였으며 분산율은 $22.674 \%$, 신뢰도는 $0.827 \%$ 로 나타났다. 요인 3 은 업체의 규모, 위치에 대한 문항으로 구성되어 '규모 - 위치요인’으로 명명하였으며 분산율은 $13.279 \%$, 신뢰도는 $0.733 \%$ 로 나타났다. 요인4는 교육 및 경력과 관 련된 문항들로 구성되어 ‘교육 - 경력요인’으로 명명하였으며 분산율 은 $8.821 \%$, 신뢰도는 $0.748 \%$ 로 나타났다.

이후 진로태도유형에 따른 취업고려요인의 차이를 알아보기 위 해 분산분석과 Duncan test를 실시한 결과는 Table 6와 같다. 진로 확신형은 인적 - 이미지, 보상 - 복지, 교육 · 경력, 규모 - 위치의 순 서로 취업을 고려하며 타 집단과 비교하여 모든 요인을 높게 고려하
는 것으로 나타났다. 반면 진로결정형, 진로독립 · 준비형, 진로무 관심형은 보상 - 복지, 인적 - 이미지, 교육 · 경력, 규모 · 위치의 순 서로 높게 나타났다. 따라서 모든 진로태도유형에서 보상 - 복지, 인 적 · 이미지는 중요시 하지만 교육 · 경력, 규모 · 위치는 상대적으로 덜 중요시하는 것을 볼 수 있다. 이러한 결과는 Son \& Lee (2004)의 연구에서 미용학과 학생들의 취업 후 불만요인으로 낮은 보수, 부당 한 인격대우, 열악한 근무환경에서 불안감을 느끼는 것으로 나타난 결과와 같은 맥락이다. 따라서 발전하는 미용분야와 달리 취업환경 은 개선이 필요한 상황으로 산업체와 대학의 노력이 필요하다. 그러 나 Kim \& Ji (2011)의 연구에서 뷰티아카데미 학생들은 기술 - 개발 관리, 고용·보상관리, 물적요인, 인적요인의 순으로 취업 시 고려 한다는 결과와 차이를 보였다. 이는 미용분야가 기술직으로 능력여 부를 미용기술과 경력으로 평가 받고 있음에도 불구하고( $\mathrm{Kim} \& \mathrm{Ji}$, 2011), 미용 산업 전공자들의 욕구수준이 과거보다 높아졌음을 의미 하며 인적 - 이미지요인, 보상 - 복지요인과 같은 개인의 안정성을 더 중요시하고 있음을 알 수 있다. 또한 월급 - 수당과 인성은 진로 태도유형을 불문하고 취업고려 시 중요한 요인임을 알 수 있다. 이 에 실무현장에서도 미용전공자들이 취업 시 고려하는 요인을 정확 히 파악하고 이를 제공할 필요가 있다.

\section{Conclusion}

본 연구는 서울과 경기도 소재 2 년제 대학 미용전공자 205 명을 대상으로 진로태도유형에 따른 진로준비행동과 취업고려요인의 차 이를 파악하였다. 연구결과는 다음과 같다.

첫째, 진로태도요인 분석결과 진로독립성, 진로결정성, 진로준비 성으로 총 3 개의 요인이 도출되었다. 이를 군집분석한 결과, 진로확 신형(35명), 진로무관심형(40명), 진로결정형(73명), 진로독립·준 비형(57명)으로 총 4 개 집단으로 분류되었다.

둘째, 진로태도유형에 따른 진로준비행동의 차이는 진로확신형 과 진로독립 · 준비형은 계획 · 준비요인이, 진로결정형과 진로무관 심형은 검색 - 대화요인이 가장 높게 나타났다. 그러나 모든 진로태 도유형에서 상담 · 실천요인은 가장 낮게 나타났다.

셋째, 진로태도유형에 따른 취업고려요인은 진로확신형은 인 적 - 이미지요인, 보상 - 복지요인의 순서로 높게 고려하며, 진로결 정형, 진로독립 · 준비형, 진로무관심형은 보상 · 복지요인, 인적 · 이미지요인의 순서로 높게 고려하고 있었다. 그러나 모든 진로태도 유형에서 교육 · 경력요인, 규모 · 위치요인은 상대적으로 덜 중요시 하는 것으로 나타났다.

이상의 결과를 바탕으로 진로확신형은 진로태도의 모든 요인이 가장 높은 집단으로 이미 자신의 진로를 결정하고 진로에 강한 확 신을 가지고 있는 집단이다. 진로준비행동에서 계획 - 준비요인, 검 색 - 대화요인은 타 집단보다 높았으나 상담 - 실천요인은 타 집단과 
비교하여 가장 낮게 나타났다. 따라서 이미 진로에 확신을 가지고 있지만 진로에 대해 심층적으로 상담을 할 수 있는 상담프로그램이 필요하다. 또한 취업고려요인에서 타 집단과 비교하여 모든 요인을 중요시하지만 특히 인적 - 이미지요인을 타 집단보다 가장 중요시하 여 진로지도 및 상담 시 미용 산업체 운영자나 직원의 인성, 기술력, 산업체의 이미지를 고려하여 취업을 돕는 전략이 필요하다.

진로무관심형은 진로태도에서 모든 요인이 가장 낮게 나타난 집 단으로 진로에 대해 무관심한 집단이다. 진로준비행동에서 검색 · 대화, 계획 · 준비요인이 타 집단보다 가장 낮게 나타났다. 이에 진
로지도 및 상담 시 진로에 대해 차근차근 계획을 세우고 진로에 대 한 자신감을 가지게 하고 이를 격려하는 전략이 필요하다. 또한 취 업고려 시 보상-복지, 인적-이미지는 중요시하지만 교육·경력, 규모 · 위치는 타 집단보다 가장 덜 중요시하는 경향을 보여 미용 산 업체 취업 시 월급수당, 휴일, 근무시간, 복지를 고려하여 취업을 돕 는 전략이 필요하다.

진로결정형은 진로태도에서 자신의 진로는 결정하였으나 진로에 대한 독립과 준비 정도는 낮은 집단이다. 진로준비행동에서 상담 실천요인이 타 집단과 비교하여 상대적으로 높게 나타나 더 많은 상

Table 4. Career preparation behaviors of career attitude types

\begin{tabular}{lccccc}
\hline & \multicolumn{5}{c}{ Career attitude type } \\
\cline { 2 - 6 } Career preparation behavior & $\begin{array}{c}\text { Career } \\
\text { confidence type } \\
(\mathrm{N}=35)\end{array}$ & $\begin{array}{c}\text { Career } \\
\text { indifference type } \\
(\mathrm{N}=40)\end{array}$ & $\begin{array}{c}\text { Career } \\
\text { determinacy type } \\
(\mathrm{N}=73)\end{array}$ & $\begin{array}{c}\text { Career independence- } \\
\text { preparation type } \\
(\mathrm{N}=57)\end{array}$ & $F$-value \\
Planning:preparation $(\mathrm{M}=3.55)$ & $4.31(\mathrm{~A})$ & $2.85(\mathrm{C})$ & $3.64(\mathrm{~B})$ & $3.46(\mathrm{~B})$ & $33.871^{* * *}$ \\
Search.conversation $(\mathrm{M}=3.51)$ & $3.84(\mathrm{~A})$ & $3.08(\mathrm{C})$ & $3.73(\mathrm{~A})$ & $3.32(\mathrm{~B})$ & $23.190^{* * *}$ \\
Counseling:practice $(\mathrm{M}=2.69)$ & $2.18(\mathrm{C})$ & $2.40(\mathrm{C})$ & $3.08(\mathrm{~A})$ & $2.69(\mathrm{~B})$ & $21.429^{* * *}$ \\
\hline
\end{tabular}

${ }^{* * *} p<0.001$; Duncan test $\mathrm{A}>\mathrm{B}>\mathrm{C}$.

Table 5. Factor analysis of career considerations

\begin{tabular}{|c|c|c|c|c|c|}
\hline Factor & Item & $\begin{array}{l}\text { Factor } \\
\text { loading }\end{array}$ & $\begin{array}{l}\text { Eigen } \\
\text { value }\end{array}$ & $\mathrm{VE} / \mathrm{CV}$ & $\begin{array}{c}\text { Reliability } \\
\text { (Cronbach's } \alpha)\end{array}$ \\
\hline \multirow{4}{*}{ Compensation'welfare } & Holiday, rest day & 0.883 & \multirow{4}{*}{3.902} & \multirow{4}{*}{$30.017 / 30.017$} & \multirow{4}{*}{0.802} \\
\hline & Working hours & 0.870 & & & \\
\hline & Employee benefits & 0.807 & & & \\
\hline & Salary, allowance & 0.555 & & & \\
\hline \multirow{5}{*}{ Personal-image } & Personality of employees & 0.898 & \multirow{5}{*}{2.948} & \multirow{5}{*}{$22.674 / 52.691$} & \multirow{5}{*}{0.827} \\
\hline & Personality of operator & 0.798 & & & \\
\hline & Introduction of professor, senior & 0.642 & & & \\
\hline & Skills of employees & 0.621 & & & \\
\hline & Image of company & 0.621 & & & \\
\hline \multirow{2}{*}{ Scale-location } & Scale of company & 0.883 & \multirow{2}{*}{1.726} & \multirow{2}{*}{$13.279 / 65.970$} & \multirow{2}{*}{0.733} \\
\hline & Location & 0.737 & & & \\
\hline \multirow{2}{*}{ Education career } & Education system & 0.904 & \multirow{2}{*}{1.147} & \multirow{2}{*}{$8.821 / 74.791$} & \multirow{2}{*}{0.748} \\
\hline & Helpful career & 0.762 & & & \\
\hline
\end{tabular}

$\mathrm{VE}$, variance explained; $\mathrm{CV}$, cumulative variance.

Table 6. Career considerations of career attitude types

\begin{tabular}{lccccc}
\hline & \multicolumn{4}{c}{ Career attitude type } \\
\cline { 2 - 5 } Career consideration & $\begin{array}{c}\text { Career } \\
\text { confidence type } \\
(\mathrm{N}=35)\end{array}$ & $\begin{array}{c}\text { Career } \\
\text { indifference type } \\
(\mathrm{N}=40)\end{array}$ & $\begin{array}{c}\text { Career } \\
\text { determinacy type } \\
(\mathrm{N}=73)\end{array}$ & $\begin{array}{c}\text { Career independence- } \\
\text { preparation type } \\
(\mathrm{N}=57)\end{array}$ & $F$-value \\
Compensation-welfare $(\mathrm{M}=4.30)$ & $4.62(\mathrm{~A})$ & $4.27(\mathrm{BC})$ & $4.10(\mathrm{C})$ & $4.38(\mathrm{~B})$ & $9.387^{* * *}$ \\
Personal-image $(\mathrm{M}=4.13)$ & $4.69(\mathrm{~A})$ & $4.13(\mathrm{~B})$ & $3.94(\mathrm{~B})$ & $4.02(\mathrm{~B})$ & $14.305^{* * *}$ \\
Scale-location $(\mathrm{M}=3.38)$ & $4.07(\mathrm{~A})$ & $2.87(\mathrm{C})$ & $3.25(\mathrm{~B})$ & $3.50(\mathrm{~B})$ & $12.701^{* * *}$ \\
Education-career $(\mathrm{M}=3.77)$ & $4.25(\mathrm{~A})$ & $3.43(\mathrm{C})$ & $3.68(\mathrm{~B})$ & $3.81(\mathrm{~B})$ & $14.850^{* * *}$ \\
\hline
\end{tabular}

${ }^{* * *} p<0.001$; Duncan test $\mathrm{A}>\mathrm{B}>\mathrm{C}$. 
담을 장려하고, 진로지도 및 상담 시 이미 결정된 진로에 대해 계획 과 준비를 돕는 전략이 필요하다. 또한 취업고려요인 중 보상 · 복지 의 고려 정도가 타 집단보다 상대적으로 낮게 나타났다.

진로독립·준비형은 자신의 진로를 독립적으로 준비하는 집단으 로, 진로준비행동과 취업고려요인이 타 집단과 비교하여 중간 정도로 나타났다. 따라서 진로지도 및 상담 시 자신의 진로에 대해 더욱 더 자신감과 확신감을 가지고 결정할 수 있도록 돕는 전략이 필요하다.

따라서 2 년제 미용전공자들은 진로태도유형에 따라 진로준비행 동과 취업고려요인에 차이를 보이고 있으므로 이들의 진로태도유형 을 고려하여 진로지도와 진로상담에 활용하면 좋을 것이다.

그러나 본 연구의 제한점은 다음과 같다. 서울과 경기도 지역의 2 년제 미용전공자를 대상으로 하여 전국의 미용전공자로 일반화할 수 없다. 또한 2 년제 학생만을 대상으로 하여 향후 연구에서는 전국 을 대상으로 하며 4년제 전공자와 2 년제 전공자를 모두 대상으로 한 연구가 필요하다. 본 연구를 바탕으로 미용 산업의 발전과 더불어 미용 산업의 인력수요와 공급의 균형을 위해 미용 산업 종사자와 미 용전공자를 위한 산업체와 학교의 노력이 필요하다.

\section{References}

Bang HJ, Park JS. The effect of career decision-making efficacy according to major satisfaction of beauty major university students. Journal of the Korean Society of Cosmetology, 20: 101-109, 2014.

Choi YJ. A study on the correlation between students satisfaction in schoolwork and employment awareness of the students majoring in beauty arts. Journal of the Korean Society of Cosmetology, 16: 140-153, 2010.

Crites JO. The career maturity inventory. CTB/McGraw-Hill, California, pp23-46, 1973.

Hong BK. The career attitude and career choice of cosmetology university students. The Korean Journal of Health Service Management, 6: 151-164, 2012.

Hong SN, Bang HJ. A development plan for selecting majors according to the curriculum at beauty-related two-year colleges. Journal of Basic Design \& Art, 14: 259-265, 2013.
Jeon HJ. A study on the effect of major selection motive and major satisfaction of college students majoring in aesthetics on employment preparation behavior. Journal of the Korean Society of Cosmetology, 21: 1212-1223, 2015.

Joo HJ, Chang MS. Class satisfaction and career decisionmaking efficacy by the self-efficacy of vocational school students majoring in cosmetology. Journal of the Korean Society of Cosmetology, 19: 1148-1160, 2013.

Kang YS, Kim ES, Lee HO, Cho MS. Job preferences of college students majoring in hair design, skin care \& make-up in Daegu \& Gyungbuk areas. Journal of the Korean Society of Cosmetology, 10: 81-92, 2004.

Kim NY, Kim CS, Kim MH, Leem MH. Analysis of satisfaction on curriculum of beauty-high school: focused on B school of Incheon. Asian Journal of Beauty and Cosmetology, 7: 423-432, 2009.

Kim SY, Ji JH. A study on the considerable factors for employment of trainees at beauty academy: focused on beauty academies in Gwangju area. Journal of the Korean Society of Design Culture, 17: 63-71, 2011.

Lee MJ, Chu SW, Lee JH. The effects of career barriers on career preparation of beauty major student: the mediation effects of career decision-making self-efficacy. Journal of the Korean Society of Beauty and Art, 17: 5771, 2016.

Park JH, Lee IH. Factor of consideration in selecting employment among the department of cosmetology students. Journal of the Korean Society of Esthetics \& Cosmeceutics, 2: 43-54, 2007.

Ryu EJ, Jeon HH. The effects of beauty-related college students' self-efficacy on the academic adjustment and the career maturity. Journal of the Korean Society of Design Culture, 21: 307-320, 2015.

Son HK, Lee YH. Recognition of their jobs against the students of beauty care. Journal of the Korean Society of Beauty and Art, 5: 247-265, 2004.

Super DE. Dimensions and measurement of vocational maturity. Teachers College Record, 57: 151-163, 1955. 


\section{국문초록}

\section{2년제 미용전공자들의 진로태도유형에 따른 진로준비행동과 취업고려요인}

최승은

성균관대학교 디자인대학원 패션학과, 서울, 한국

목적: 본 연구는 2 년제 미용전공자들의 진로태도유형에 따른 진로준비행동과 취업고려요인을 파악하고자 하였다. 방법: 총 205 부 가 최종분석에 사용되었으며 통계프로그램을 이용하여 요인분석, 신뢰도분석, 군집분석, 분산분석을 실시하였다. 결과: 진로태도 유형을 분류한 결과, 진로확신형, 진로무관심형, 진로결정형, 진로독립 · 준비형으로 총 4 개의 집단이 나타났다. 진로확신형은 진로 준비행동에서 계획 - 준비, 검색 - 대화요인은 높으나 상담 - 실천요인은 가장 낮게 나타났으며, 취업고려요인에서 타 집단과 비교 하여 모든 요인을 중요시하지만 특히 인적 - 이미지를 가장 중요시하고 있었다. 진로무관심형은 진로준비행동에서 상담 · 실천요인 을 제외한 모든 요인이 타 집단에 비해 가장 낮았으며, 취업고려 시 보상 - 복지요인을 중요시하고 있었다. 진로결정형은 진로준비 행동에서 상담 · 실천요인이 타 집단과 비교하여 상대적으로 높게 나타났으며, 취업고려요인 중 보상 - 복지의 고려 정도가 타 집단 보다 상대적으로 낮게 나타났다. 진로독립 - 준비형은 진로준비행동과 취업고려요인이 타 집단과 비교하여 중간 정도로 나타났다. 결론: 2 년제 미용전공자들은 진로태도유형에 따라 진로준비행동과 취업고려요인에 차이를 보였다. 따라서 이들의 진로태도유형을 고려하여 진로지도와 진로상담에 활용할 필요가 있다.

핵심어: 진로태도, 진로준비행동, 취업고려, 2년제 대학, 미용전공자

\section{참고문헌}

강영숙, 김은숙, 이현옥, 조명숙. 미용관련학과 재학생들의 직업선호도에 관한 연구. 한국미용학회지, 10: 81-92, 2004. 김남연, 김창숙, 김미현, 임미혜. 미용관련 고교의 교과과정 만족도 분석: 인천의 B학교를 중심으로. 아시안뷰티화장품학술지, 7: 423-432, 2009.

김선영, 지정훈. 뷰티아카데미 교육생의 취업 시 고려요인 연구: 광주광역시 뷰티아카데미를 중심으로. 한국디자인문화학회 지, 17: 63-71, 2011.

류은주, 전형희. 미용관련 전공 대학생의 자기효능감이 학업적 적응 및 진로성숙도에 미치는 영향. 한국디자인문화학회지, $21:$

307-320, 2015.

박제희, 이인희. 미용 관련학과 대학생의 진로선택 시 고려사항 분석. 한국피부미용향장학회지, 2: 43-54, 2007.

방효진, 박정신. 미용전공 대학생의 전공만족도가 진로결정효능감에 미치는 영향. 한국미용학회지, 20: 101-109, 2014. 손해경, 이용환. 미용학과 학생들의 직업인식도. 한국인체미용예술학회지, 5: 247-265, 2004.

이미지, 추소원, 이정현. 미용전공 대학생의 진로장벽이 진로준비행동에 미치는 영향. 한국인체미용예술학회지, 17: $57-71$, 2016.

전현진. 미용전공 대학생의 전공선택 동기와 전공만족도가 취업준비행동에 미치는 영향. 한국미용학회지, $21: 1212-1223$, 2015.

주효정, 장미숙. 직업전문학교 미용전공생의 자기효능감에 따른 수업만족도와 진로결정효능감. 한국미용학회지, 19: $1148-$ 1160, 2013.

최영진. 미용관련학과 학생들의 취업의식과 학과만족도에 관한 연구. 한국미용학회지, 16: 140-153, 2010.

홍보경. 미용학과 학생들의 진로태도와 진로선택성향. 보건의료산업학회지, 6: 151-164, 2012.

홍수남, 방효진. 2 년제 미용관련대학 교과과정에 따른 전공선택 발전방안. 기초조형학연구, 14: 259-265, 2013. 


\section{中文摘要}

\section{根据2年制美容专业者的职业态度类型研究职业准备行为和就业考虑因素}

\section{崔升銀}

成均馆大学设计大学院时装设计系, 首尔, 韩国

目的: 根据2年制美容专业者的职业态度类型, 探讨职业准备行为和就业考虑因素。方法: 共205份作为最终分析, 采用 统计软件进行因子分析, 可靠性分析, 聚类分析, 方差分析。结果：根据职业态度类型分为四种类型：职业确信型，职 业冷漠型, 职业确定型, 职业独立 ·准备型。职业确信型在职业准备行为中, 计划 ·准备, 搜索·对话因素方面比较高, 而咨询 ·实践因素方面最低; 在就业考虑因素中, 与其他群体相比所有因素被认为是重要的, 然而最重要的因素是个人 图像。职业冷漠型, 在职业准备行为中, 除了咨询 · 实践因素之外, 所有因素都低于其他群体, 然而, 在就业考虑因素 中, 最重视的是补偿 - 福利因素。职业确定型, 在职业准备行为中, 与其他群体相比咨询 ·实践因素比较高, 而在就业考 虑因素中, 补偿·福利因素相对比其他群体较低。职业独立 ·准备型, 在职业准备行为和就业考虑因素中, 与其他群体相 比表现为中等程度。结论: 根据2年制美容专业者的职业态度类型, 职业准备行为和就业考虑因素上存在着差异。因此, 有必要根据职业态度类型来进行职业指导和职业咨询。

关键词: 职业态度, 职业准备行为, 就业考虑, 2年制大学, 美容专业者 